\title{
Progress in Tetraploid Wheat Breeding through the Use of Synthetic Hexaploid Amphiploids
}

\author{
N. Daskalova ${ }^{1}$, S. Doneva ${ }^{2}$, Y. Stanoeva ${ }^{2}$, I. Belchev ${ }^{2}$ and P. Spetsov ${ }^{3 *}$ \\ 1Plant Production Department, Technical University, Varna 9010, Bulgaria \\ ${ }^{2}$ Dobrudzha Agricultural Institute, 9520 General Toshevo, Bulgaria \\ ${ }^{3}$ Aksakovo Center, 9154 Aksakovo, Varna region, Bulgaria
}

(Received 20 May 2018; Accepted 28 September 2018;

Communicated by P.S. Baenziger)

\begin{abstract}
Four amphiploid lines (SHW) based on T. monococcum $(\mathrm{Tm})$ and T. boeoticum $(\mathrm{Tb})$ were crossed to $T$. durum varieties to generate 13 combinations. Field germination and winter survival of hybrid plants in $\mathrm{F}_{2}$ were assessed. Among all crosses, those with SHW8A-Tb and SHW9A-Tm showed highest field germination but with different degrees of spike fragility. The variation on seed number and weight per main spike was studied in $\mathrm{F}_{4-6}$ from SHW8A$\mathrm{Tb} /$ Progres and SHW5A-Tb/Severina crosses after individual selection for these traits. Ten lines with durum phenotype from the former and three genotypes with dicoccum plant shape from the latter cross were developed. SDS-PAGE indicated the presence of HMW-GS 1 Ax $2 *+1$ Aynull subunits in four lines, among which $1 \mathrm{Ax} 2 *$ was inherited from T. boeoticum acc.110 through SHW8A-Tb. Most of the selected genotypes possessed $\gamma$-gliadin45, which was relating to good end-use quality. Powdery mildew testing showed that all progenies resulted from the SHW8A-Tb/Progres were susceptible to 12 races of the pathogen, while three lines derived from the SHW5A-Tb/Severina cross behaved differently: G32 expressed resistance to six, G33 to 2, and G34 to 5 races. The selected genotypes from crosses involving SHW with T. boeoticum exhibited good breeding performance compared to tetraploid wheat parents, and might be of breeding interest to further research.
\end{abstract}

Keywords: Triticum species, synthetic amphiploids, recombinants, seed storage proteins, powdery mildew resistance

Abbreviations: SHW - synthetic hexaploid wheat; HMW-GS - high-molecular-weight glutenin subunits; Bgt - Blumeria graminis f. s. tritici; PM - powdery mildew

\section{Introduction}

Interspecific hybridization is a reliable method to transfer useful genetic materials from one species (donor) to another one (recipient). Development of new lines from wide crosses involves the production of $\mathrm{F}_{1}$ hybrids, their backcrossing to cultivated parent, and selection of individuals with the desired feature(s) of the donor species. Often the selected plants contain some linkage drag, of which spike fragility, reduced fertility and degree of necrosis are frequently occurred (Valkoun 2001; Zaim et al. 2017). 
The genus Triticum L. (subtribe Triticinae) is one of the most important genera in the family Poaceae and includes four species Triticum monococcum L., T. urartu Thum. ex Gandil., T. boeoticum Boiss. and T. sinskajae A. Filat. et Kurk. at diploid level (Goncharov 2011). There are several authors reporting that $T$. monococcum, as one of the first crops in Fertile Crescent, was domesticated through T. boeoticum (for a review see Zaharieva and Monneveux 2014). Evolutionary, durum wheat $\left(2 \mathrm{n}=28, \mathrm{BBA}^{\mathrm{u}} \mathrm{A}^{\mathrm{u}}\right)$ has received the A genome from T. urartu $\left(\mathrm{A}^{\mathrm{u}} \mathrm{A}^{\mathrm{u}}\right)$, while T. boeoticum donated $\mathrm{A}^{\mathrm{b}}$ genome to T. monococcum $\left(\mathrm{A}^{\mathrm{b}} \mathrm{A}^{\mathrm{b}}\right)$ and T. zhukovskyi $\left(\mathrm{GGA}^{\mathrm{u}} \mathrm{A}^{\mathrm{u}} \mathrm{A}^{\mathrm{b}} \mathrm{A}^{\mathrm{b}}\right)$ (Goncharov 2011). Accessions of T. boeoticum manifested resistance to powdery mildew (He et al. 2007; Elkot et al. 2015), stripe rust (He et al. 2007; Chhuneja et al. 2012), stem rust (Olson et al. 2010), insect resistance (Radchenko 2011), tolerance to drought and other stresses (Valkoun 2001; Liu et al. 2015), variability in HMW glutenins (Hu et al. 2012) and LMW glutenins (Khoshro et al. 2010; Cuesta et al. 2017). The diploid wheat carried interesting traits for adaptation to climatic change in the Mediterranean region (Mac Key 2005).

Synthetic hexaploid wheats are developed by artificially crossing the tetraploid wheat cultivars or their hybrids/advanced breeding lines (Triticum turgidum L., $2 \mathrm{n}=4 \mathrm{x}=28$, BBA $\left.^{u} A^{u}\right)$ with different accessions of diploid Triticum and Aegilops species $(2 \mathrm{n}=2 \mathrm{x}=14)$. The $\mathrm{F}_{1}$ hybrids $(2 \mathrm{n}=3 \mathrm{x}=21)$ produced as a result of these crosses, were treated with colchicine which caused chromosome doubling and formed fertile hexaploid genotypes known as synthetic hexaploid wheats (SHW). It is well documented that synthetic hexaploid germplasm can be exploited for resistance and tolerance for leaf rust (Puccinia tritici), stripe rust (Puccinia striiformis), mineral toxicities, drought, salinity (Colmer et al. 2006; Trethowan and Mujeeb-Kazi 2008; Zaharieva et al. 2010), heat, cold, sprouting, water logging (Villareal et al. 2001; van Ginkel and Ogbonnaya 2007), powdery mildew (Blumeria graminis f. sp. tritici), loose smut (Ustilago tritici), cereal cyst nematode (Heterodera avenae), and variability in seed storage proteins (Lage et al. 2006; Mujeeb-Kazi et al. 2013; Dai et al. 2015).

Synthetic hexaploids (Triticum turgidum/T. boeoticum, $2 \mathrm{n}=42, \mathrm{BBA}^{\mathrm{u}} \mathrm{A}^{\mathrm{u}} \mathrm{A}^{\mathrm{b}} \mathrm{A}^{\mathrm{b}}$ ) were created to explore for novel genes from tetraploid and diploid wheats that can be used for tetraploid cultivated (durum, emmer) and common wheat improvement (Gorham 1990; Ahmed et al. 2014). For the period 1980-2017 Mujeeb-Kazi et al. (2017) published 101 publications about the development, assessment and usage of synthetic wheats in breeding, among which only 2 studies dealt with the A- and B-genome synthetics. Rafique et al. (2012) found that from 104 lines of A-genome amphiploids (AAB$\mathrm{BA}^{\mathrm{m}} \mathrm{A}^{\mathrm{m}} / \mathrm{A}^{\mathrm{u}} \mathrm{A}^{\mathrm{u}}$ ), $53.6 \%$ were resistant to powdery mildew (incited by Blumeria graminis f. sp. tritici) at the seedling stage, while Ahmed et al. (2013) indicated 17 out of 26 seedling-resistant amphiploids to stripe rust being resistant at the adult plant stage, too. These novel amphiploid stocks, created at the CIMMYT-Mexico, were derivatives of 20 durum cultivars and accessions of the $\mathrm{A}^{\mathrm{b}}$ (T. monococcum) and $\mathrm{A}^{\mathrm{u}}$ genome (T. urartu). Phenotypically, they were tall, late maturing, easy to thresh, with good fertility and rachis fragility. The last mentioned trait is primarily controlled by genes located on the homoeologous group 3 chromosomes. All wild wheats have a btittle rachis leading to 
shattering of either the whole spike or individual spikelets (Sood et al. 2009). In addition to the Q gene, three loci $B r 1, B r 2$ and $B r 3$ govern the rachis character. In tetraploid wheats, recessive alleles of two of them $(\mathrm{Br} 2$ and $\mathrm{Br} 3)$ determine non-brittle rachis. Species of T. monococcum, T. dicoccum and T. timopheevii possess a specific type of brittle rachis being disarticulated with a slightest mechanical pressure at maturity (Konopatskaia et al. 2016). The hexaploid amphiploids with $\mathrm{A}^{\mathrm{b}}$ and $/$ or $\mathrm{A}^{\mathrm{u}}$ genome are considered as valuable stocks to enhance diversity in durum as well as bread wheat breeding (Mujeeb-Kazi et al. 2017). Main tasks in the breeding improvement of emmer and durum wheats are connected with increasing resistance to abiotic (frost and drought) and biotic (diseases) stress factors. Along with the productivity per unit of area, grain quality has recently appeared as very important trait too. T. boeoticum is widely distributed in Bulgaria, but with limited space along the Bulgarian Black Sea coast (Spetsov et al. 2006). We collected eight samples between Kamchia river and Burgas. The only accession No. 110 showed resistance to both investigated powdery mildew and leaf rust, thus being estimated as valuable resource for wheat improvement and involved in creation of several amphiploids. Li et al. (2016) detected eight Glu-A1x alleles in T. monococcum ssp. monococcum, and five from them were novel $\left(G l u-A 1^{m}-b, G l u-A 1^{m}-c, G l u-A 1^{m}-d\right.$, Glu-A1 $1_{-} g$ and $\left.G l u-A 1^{m}-h\right)$. Thus, $\mathrm{A}^{\mathrm{b}}$ genome from diploid Triticum species offers new possibilities to enrich the tetraploid wheat genetic base.

The aim of this study was to explore hexaploid amphiploids based on Triticum monococcum $\left(\mathrm{A}^{\mathrm{b}} \mathrm{A}^{\mathrm{b}}\right)$ L. and T. boeoticum $\left(\mathrm{A}^{\mathrm{b}} \mathrm{A}^{\mathrm{b}}\right)$ Boiss. accessions in breeding of tetraploid wheat germplasm with complex agronomic traits such as high field germination, winter hardiness, grain quality and yield, and biotic stress resistance. The selected recombinants with promising seed set were assessed for seed storage proteins and powdery mildew resistance for their characterization as potential resources of wheat improvement.

\section{Materials and Methods}

\section{Plant materials}

Several amphiploids $\left(\mathrm{BBA}^{\mathrm{u}} \mathrm{A}^{\mathrm{u}} \mathrm{A}^{\mathrm{b}} \mathrm{A}^{\mathrm{b}}\right)$ involving T. monococcum and T. boeoticum samples have been developed in the Dobrudzha Agricultural Institute-GeneralToshevo, Bulgaria, and implicated into crosses with $T$. durum Desf. cultivars (Table 1). $\mathrm{F}_{2}$ seeds of 13 crosscombinations studied were sown in the field to select best individuals for field germination and winter survival. $\mathrm{F}_{3}$ plants were germinated in Petri dishes and grown in greenhouse to evaluate spike fragility. This trait was assessed at maturity by visualizing each plant when the main spike is held by hand with slight pressing. If the top spikelets disintegrated, then the plant was marked as fragile one. The brittleness occurred only at the apical spikelets of the spike which makes this manual action easy to divide fragile vs. not fragile plant. Ten genotypes selected in $\mathrm{F}_{5}$ generation from SHW8A-Tb/Progres and three-from SHW5A-Tb/Severina crosses, were tested for field performance. 
Table 1. Pedigree of amphiploid lines $\left(\mathrm{BBA}^{\mathrm{u}} \mathrm{A}^{\mathrm{u}} \mathrm{A}^{\mathrm{b}} \mathrm{A}^{\mathrm{b}}\right)$ and their application in different crosses

\begin{tabular}{|c|c|c|}
\hline $\begin{array}{c}\text { Breed. } \\
\text { No }\end{array}$ & Pedigree & Pollinator \\
\hline SHW2A-Tm & (DHL ${ }^{1 / T}$. monococcum acc. dai) & Argonavt $^{3}$, Beloslava $^{4}$ \\
\hline SHW5A-Tb & (T. dicoccum acc. dai/T. boeoticum acc. $110^{2}$ ) & $\begin{array}{l}\text { Argonavt, Gergana }{ }^{4} \\
\text { Perlina }^{3}, \text { Progres }^{4} \\
\text { Severina }^{4}, \text { Strumchanka }^{5}\end{array}$ \\
\hline SHW8A-Tb & (T. durum var. Md-3/T. boeoticum acc. $110^{2}$ ) & Progres \\
\hline SHW9A-Tm & (T. dicoccum acc. dai/T. monococcum acc. dai) & Argonavt, Gergana Martondur-36, Progres \\
\hline & & Total: 13 cross-combinations \\
\hline
\end{tabular}

${ }^{1} \mathrm{DHL}=$ originated from $T$. durum cultivar Gergana/T. dicoccum acc. dai cross; ${ }^{2} T$. boeoticum accession (synonym T. monococcum ssp. aegilopoides $)=$ collected from the Black Sea coast $\left(\right.$ Spetsov et al. 2006); ${ }^{3}$ Argonavt, Perlina $=T$. durum varieties from Ukraine; ${ }^{4}$ Beloslava, Gergana, Progres, Severina = Bulgaria; ${ }^{5}$ Strumchanka $=$ Macedonia; ${ }^{6}$ Martondur-3 $(\mathrm{Md}-3)=$ Hungary.

\section{Soil and climatic conditions}

The soil of the experimental site was haplic chernozem. In 2014/15, the weather conditions were characterized by higher precipitation level $(518 \mathrm{~mm})$ than $2015 / 16(485 \mathrm{~mm})$. The temperature in October was optimal for the seed germination in the whole period. Snow depth on the field amounted to on average five $\mathrm{cm}$ on the second January. The minimum temperatures of $-10{ }^{\circ} \mathrm{C}$ occurred in December and February of the first year and reached $-12{ }^{\circ} \mathrm{C}$ in December and January of the second year. The winter conditions in 2014-2016 were different concerning the presence of snow cover and duration of minimal freezing temperatures. More rains fell in the last three months of the second year that accelerated plant development. Concerning the four factors (average minimum temperature, average maximum temperature, rainfall and snowfall), the meteorological conditions were considered good for plant germination and for growth to harvesting during the whole period.

\section{Field experiment}

Wheat progenies $\left(\mathrm{F}_{2-6}\right)$ were grown in a crop rotation field in Varna $\left(43^{\circ} 12^{\prime} \mathrm{N}, 27^{\circ} 54^{\prime} \mathrm{E}\right.$, $50 \mathrm{~m}$ ), Bulgaria, during 2012-2016. Forage peas (Pisum sativum) preceded and no fertilizers and pesticides were applied during the plant growing seasons. The sowing dates were typical for Varna conditions, between 10-20 Oct. The seeds were manually planted on single-row plots at 20 seeds per row $1 \mathrm{~m}$ long and at an inter-row spacing of $40 \mathrm{~cm}$ using randomized design with two replications. The evaluation of germination was done in the autumn at 1-2 leaf stage and the winter survival was calculated using all available plants for each line in the beginning of spring regrowth in March. Common wheat variety 'Sadovska ranozreika-4' was sown as a standard check cutlvar at regular intervals after every 25 rows. Each family obtained from a selected plant consisted of 20 seeds, sown in two replications. The selected 13 genotypes were tested on single-row plots as mentioned above, for two years (2014-2016) along with the durum parents Progres and Severina. 


\section{Protein extraction and SDS-PAGE}

Ten grains from each line were crushed and ground to powder. Gliadins were first extracted in $70 \%$ ethanol and protein fractions were separated by A-PAGE using $8 \%$ polyacrylamide gel under constant $10{ }^{\circ} \mathrm{C}$ (Khan et al. 1983). Extraction of HMW-GS was performed in four stages (Singh et al. 1991). The electrophoresis run on a vertical apparatus in two ways: a) classical one-dimensional $12 \%$ polyacrylamide gel; b) one-dimensional $12 \%$ polyacrylamide gel SDS-PAGE with addition of 4M urea (Lafiandra et al. 1993). Protein fractions were investigated and designated through the universal system for arrangement and numbering of glutenins (Payne and Lawrence 1983). The catalogue for gliadins recording in common wheat (Metakovsky 1991) was also applied.

\section{Powdery mildew test}

Twelve Blumeria graminis f. sp. tritici (Bgt) races were collected from different parts of Bulgaria and selected from single spore isolates. The test for mildew resistance was conducted on plants in second leaf stage, grown in plastic containers. Inoculation methods, incubation conditions and disease assessment followed Lutz et al. (1992). Each wheat parent/line was tested using two replications, each consisting of 8 to 10 individuals. Disease response patterns were recorded ten days after inoculation using a quantitative scale of 0 to 10 , where $0=$ no visible disease symptoms and $10=100 \%$ leaf area covered with sporulating colonies. Three major classes of host reactions were distinguished: $r=$ resistant ( $0-20 \%$ infection level), $\mathrm{i}=$ intermediate $(20-50 \%$ infection $), \mathrm{s}=$ susceptible $(>50 \%$ infection). Where accessions were heterogeneous for response, they were recorded as ' $\mathrm{r}, \mathrm{i}$ ' or ' $\mathrm{i}, \mathrm{s}$ ' depending on level of infection.

\section{Statistical analysis}

Mean data of the two years experiment were statistically evaluated by analysis of variance to determine significant differences $(p<0.05)$ between wheat genotypes with Tukey test using Assistat version 7.7 beta (Silva and Azevedo 2016) and compared to durum cultivars Progres and Severina (Tables S2-S3*).

\section{Results}

\section{Application of four amphiploids in wheat breeding}

At least $15 \mathrm{~F}_{2}$ seeds per cross-combination were sown in the field for a total of 197 seeds (Table S1). A small part of them germinated, 31 (15.7\%) and about half of them survived $(16,51.6 \%)$ during the winter of 2011/12. No seeds germinated from the $5 \mathrm{~A}-\mathrm{Tb}$ /Progres cross. The best crosses were SHW8A-Tb/Progres and SHW9A-Tm/Progres by 5 plants, and SHW5A-Tb/Gergana and SHW5A-Tb/Perlina by 4 plants each. Sixteen plants from

\footnotetext{
*Further details about the Electronic Supplementary Material (ESM) can be found at the end of the article.
} 
eight crosses were harvested and 11 from them produced $218 \mathrm{~F}_{3}$ seeds $(19.8$ seeds per plant on average). All $\mathrm{F}_{3}$ plants were grown in the greenhouse and analyzed for spike fragility.

Three crosses, SHW5A-Tb/Strumchanka, 8A-Tb/Progres and 9A-Tm/Argonavt did not express this trait at maturity, while the other three crosses showed brittleness from $7.8 \%$ (5A-Tb/Gergana) to $28.6 \%(5 \mathrm{~A}-\mathrm{Tb} /$ Severina). They involved SHW5A-Tb and SHW9A-Tm in their pedigree, distinguished by a high degree of spikelet disarticulation (Table S1). $\mathrm{F}_{4}$ plants were grown in the field to screen the materials for sprouting and winter survival. Individual plant selection was applied for grain number (NGS) and weight per spike (GWS). Best results were obtained in progenies of SHW8A-Tb/Progres, where plant height varied from 68 to $127 \mathrm{~cm}$, NGS - 36 to 54, GWS - 0.9 to $2.0 \mathrm{~g}$, compared to the same traits in Progres, $107 \mathrm{~cm}, 55$ and $2.3 \mathrm{~g}$, respectively (data not shown). Similar effects were found in the SHW5A-Tb/Severina cross 85-140 cm for height, 3862 for grains and 1.1-2.3 g for grain weight per main spike, compared to $90 \mathrm{~cm}, 55$ and $2.2 \mathrm{~g}$ for Severina (data not shown). Some of the selected progenies in $\mathrm{F}_{4}$ equaled or slightly surpassed Severina on the measured features.

Ten lines were selected from the SHW8A-Tb/Progres cross and tested for field performance in comparison to durum wheat Progres (Table S2). No differences were detected on SL, SW, NGS and GWS. Some of the genotypes revealed differences for PH, TN, NSS and TKW. The tallest line was G21 $(109 \mathrm{~cm})$ and the shortest one - G27 $(77 \mathrm{~cm})$. Three lines, G16, G22 and G25 produced more productive tillers (7-8.4) than Progres (3.5). Variability between genotypes was recorded on NSS, SW, NGS, GWS and TKW. G18 expressed the highest values on NSS (23), SW (5.2), NGS (62) and GWS (3.8), which supported this line as the best one among all progenies selected.

Three lines were generated from the cross of Severina and grown in the field compared to their wheat parent (Table S3). Differences were detected between genotypes and durum parent on all traits studied, except TN. The lines exceeded Severina on spike length only $(p<0.05)$, but they were inferior for the rest traits, excluding plant height. G34 had the tallest stem with spikes producing high number of spikelets and seeds, but reduced values on GWS and TKW (1.9 and 42 contrasted to 4.3 and 66 for Severina).

\section{Seed storage proteins}

The selected genotypes were compared to SHW and their durum wheat parents (Table $\mathrm{S} 4)$. The protein pattern of SHW8A-Tb $(1 \mathrm{Ax} 2 *+1 \mathrm{Ay} 1-7+8-\gamma 45)$ was a combination between durum wheat cv. Martondur-3 and T. boeoticum acc.110, while the variety Progres had a different composition, 1Axnull-17+18- $\gamma 42$. From the ten progenies designated from the cross of Progres, six were homogeneous for arrangement of glutenins and gliadins (seeds in $F_{6}$ generation) and the other four genotypes (G18, G21, G27 and G28) exerted different constitution of bands regarding the presence/absence of $\gamma$-gliadins 42 and 45 . From them, G27 and G28 had the subunit 1Ax2* which is the characteristic of SHW8A$\mathrm{Tb}$, inherited from the diploid wheat acc.110, while G18 and G21 expressed 1Axnull, that is a typical feature of durum parents Martondur-3 and Progres (Table S4). Two families, 


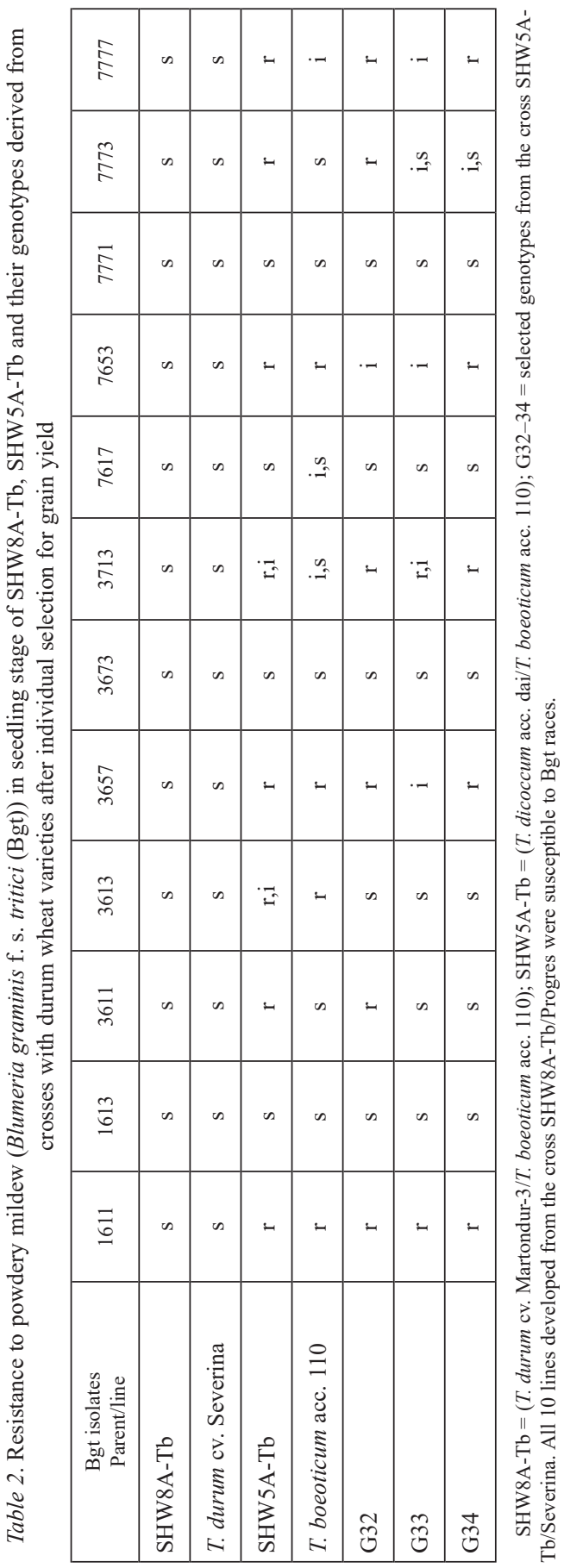

Cereal Research Communications 47, 2019 
G27-7 and G28-5 exhibited a protein pattern of $1 \mathrm{Ax} 2 *-17+18-\gamma 45$. Not one of the selected lines contained a band 1Ay1 of SHW8A-Tb, which was registered in the wild progenitor acc. 110. Five lines with homogeneous HMW-GS structure contained $\gamma$-gliadin45 while two progenies (G18-3 and G21-3) were found not to possess the basic component at Gli-B1.

According to HMW-GS, SHW5A-Tb displayed two profiles, $1 \mathrm{Ax} 2 *+1$ Aynull, and 1Ax1+1Aynull, which were inherited in all three selected lines (Table S4). Seed protein constitutions of G32 and G33 were identical at all investigated loci, 1 Axnull+1 Aynull-7+8, while G34 had different banding pattern, 1Ax2*+1Aynull-6+8. Gliadin $\gamma 45$ in durum parent Severina was not transferred into the three fixed offsprings. As for glutenins at Glu$B 1$, they expressed subunits deriving from their parents, $6+8$ and $7+8$.

\section{Resistance to powdery mildew in seedlings}

SHW8A-Tb showed susceptibility to all races used, while SHW5A-Tb manifested resistance to eight of them: indicating reactions ( $r$ ) to six races and intermediate one (r,i) to races 3613 and 3713 (Table 2). T. boeoticum acc. 110 exhibited resistance to four pathotypes (1611, 3613, 3657 and 7653), and intermediate response to 7777. T. durum variety Severina was susceptible to the powdery mildew pathogen. Line G32 showed resistance to six races and intermediate reaction to 7653 . G33 was resistant only to 1611 , with variable response $(\mathrm{r}, \mathrm{i})$ to race 3713 . G34 manifested seedling resistance to five strains (1611, $3657,3713,7653$ and 7777), as G32 did, and the differences between the two lines lied in their reactions to 3611, 7653 and 7773. The results indicated, that the SHW5A-Tb and its derivatives G32 and G34 were the lines with resistance expressed to about in half of Bgt races used in the study.

\section{Discussion}

Around 195 A-genome SHW have been developed at CIMMYT-Mexico. Up to now, applied usage of the A-genome synthetics has not been documented, although they are considered as valuable stocks to enhance diversity in durum as well as bread wheat breeding (Mujeeb-Kazi et al. 2017).

Several authors studied them for their valuable traits to enhance diversity in durum as well as bread wheat breeding, mainly for resistance/tolerance to biotic stresses (Ahmed et al. 2013, 2014). To our knowledge at present, no information is available for transfer of traits to cultivated wheat in crosses with A-genome synthetics. Classical are the examples when the diploid Triticum boeoticum (synonym T. monococcum ssp. aegilopoides) was a donor for successful transfers into bread wheat. Rogers et al. (1997) managed to introgress two alleles, Glu-A1r encoding HMW glutenin subunits $39+40$ and Glu-A1s encoding other glutenin fractions $41+42$ from two accessions of $T$. boeoticum into common wheat. Using near-isogenic lines, the authors demonstrated that the genetic changes resulted in diminished dough stickiness, improved stability during mixing and gluten strength. Dhaliwal et al. (2002) reported results for the effect of transferred protein alleles 
from different accessions of T. boeoticum into T. durum cv. PBW34 with mean increase in SDS-sedimentation value, but without revealing the yielding capacity of durum derived lines.

HMW-GS are controlled by Glu-1 loci, each locus consists of two tightly linked genes that encode one larger $\mathrm{x}$ - and one smaller y-type subunit. Variation in the Glu-A1x locus in common wheat is scare, as most bread wheat varieties have only one of the three main alleles at this locus (Glu-A1a, Glu-A1b and Glu-A1c), which encoded 1Ax1, 1Ax2* and 1Axnull, respectively. Ribeiro et al. (2013) reported a new x-type HMW-GS in Portuguese wheat landrace Barbela encoded at the Glu-A1 locus and named it as $1 A x 1.1$. A little later, this protein was described by Daskalova et al. (2016) in three synthetic hexaploid lines (Triticum turgidum ssp. dicoccum/Aegilops tauschii) and their tetraploid wheat parents. Thus, the incorporation of $G l u-A 1$ alleles from diploid species into cultivated wheat is important for the quality improvement.

The 1Ay subunit encoded by the y-type gene at the Glu-A1 locus has been considered to be always silent in hexaploid wheat (Halford et al. 1989). However, a number of $1 A y$ alleles were found in diploid species T. urartu and related species T. monococcum and T. boeoticum (Hu et al. 2010, 2012). T. boeoticum accession 110 expressed the subunit 1 Ay1 in combination with $1 \mathrm{Ax} 2 *$ in this study. Synthetic $8 \mathrm{~A}-\mathrm{Tb}$ exerted the same glutenin composition, differing from that of durum variety Martondur-3. Most of the selected genotypes had 1Axnull at Glu-A1, which is the same as its durum parent Progres, but three lines expressed $1 \mathrm{Ax} 2 *$, inherited from the wild diploid progenitor acc. 110 through SHW8A-Tb. Li et al. (2016) suggested that such HMW-GS variations in ancestral species provided candidate genes for further wheat quality improvement. Durum variety Severina expressed a subunit 1Axnull, which was present in 2 families (G32 and G33), selected from SHW5A-Tb/Severina cross, while G34 possessed 1Ax2* inherited from T. boeoticum through SHW5A-Tb. Accessions with expressed 1Ax and 1Ay subunits are potential candidate for wheat quality breeding. Here, 1Ay is silent in all new genotypes. The replacement of the silenced 1Ay in durum wheat by an expressed 1Ay may further increase the number of glutenins and thus improve flour processing quality (Alvarez et al. 2009).

Gliadins are seed storage proteins in wheat and the key determinants of seed quality. In $T$. durum, the presence of $\gamma$-gliadin 45 was considered as a marker for high pasta quality, whereas $\gamma$-gliadin42 was associated with low quality (Varzakas et al. 2014; De Santis et al. 2017). From the 10 lines selected (SHW8A-Tb/Progres), only G31 was homogeneous for $\gamma$-gliadin42, while G27 and G28 still segregated for this trait (Table S4). From the rest seven lines, four (G16, G17, G22 and G23) were similar, containing only $\gamma$-gliadin45, with a potential for high grain quality. In wheat progenitor Triticum urartu, gliadins have proved useful in the study of anatomical structure, variability and evolutionary changes (Zhang et al. 2015).

Powdery mildew test showed that genotypes derived from only SHW5A-Tb/Severina cross behaved differently to the 12 Bgt races used. Two progenies from this cross (G32 and G34) expressed resistance to powdery mildew (PM) in seedlings. G32 manifested resistance to 6 races $(1611,3611,3657,3713,7773$ and 7777), whereas G34 showed resistance to 5 strains (Table 2). Line G33 was only resistant to race 1611. The first two 
lines possessed seedling PM resistance, suggesting they are valuable sources of major resistance genes. Screening of the two amphiploids indicated a sharp difference in resistance between them. In case of SHW8A-Tb, the suppression of resistance was observed probably due to the durum parent variety Martondur-3. On condition of SHW5A-Tb, the resistance maybe contributed either by the diploid progenitor acc. 110 or emmer wheat acc. dai, or both. The two synthetic wheats involved the $\mathrm{A}^{\mathrm{b}}$ genome of T. boeoticum, possessing genes for powdery mildew resistance (He et al. 2007; Chhuneja et al. 2012; Zaharieva and Monneveux 2014). Elkot et al. (2015) demonstrated marker assisted transfer of PM resistance from the wild einkorn to bread wheat. Emmer based synthetic backcross derived lines were found to have a high level of resistance to greenbug (Schizaphis graminum) (Lage et al. 2003) and Russian wheat aphid (Diuraphis noxia) (Lage et al. 2004) as well as good grain quality (Lage et al. 2006). Zaharieva et al. (2010) gave references for promising strains of emmer wheat that are being used to develop new prebreeding germplasm available in breeding programs worldwide.

When assessing the genetic diversity in SHW $(T$. dicoccum $/ T$. boeoticum $) \times$ durum wheat derived lines, a question arose of how much 'wild' variation remains after selection for agronomic type. Years ago, Dhaliwal et al. (2002) and Suman et al. (2004) reported results for the effect of transferred protein alleles from different accessions of $T$. boeoticum into T. durum cv. PBW34 with mean increase in SDS-sedimentation value. Zaim et al. (2017) investigated seventeen wide crosses of durum wheat varieties with $T$. dicoccoides, T. araraticum and Ae. speltoides, emphasizing their disease resistance, yield stability and industrial quality across Mediterranean sites. The authors did not identify any negative drag in the use of wide crosses for improving durum wheat, with the partial exception of yellow pigment. In our study, a variation on seed number and weight per main spike was registered in $\mathrm{F}_{4-6}$ of SHW8A-Tb/Progres and SHW5A-Tb/Severina crosses permitting selection of recombinants with a number of valued agronomic traits.

\section{Acknowledgement}

We thank the Dobrudzha Agricultural Institute for providing facilities to carry out the crosses, selection and biochemical studies on synthetic hexaploid wheats and their derived lines.

\section{References}

Ahmed, S., Bux, H., Rasheed, A., Kazi, A.G., Rauf, A., Mahmood, T., Mujeeb-Kazi, A. 2013. Stripe rust resistance in Triticum durum-T. monococcum and T. durum-T. urartu amphiploids. Austr. Plant Pathol. 43:109113.

Ahmed, S., Bux, H., Kazi, A.G., Channa, A.W., Qureshi, S.T., Soomro, A.A., Sial, M.A., Rauf, A., MujeebKazi, A. 2014. Molecular diversity in some A-genome wheat amphiploids $(2 n=6 x=42$; BBAAAA). Pak. J. Biotech. 11:111-121.

Alvarez, J., Caballero, L., Nadal, S., Ramírez, M., Martín, A. 2009. Development and gluten strength evaluation of introgression lines of Triticum urartu in durum wheat. Cereal Res. Commun. 37:243-248.

Chhuneja, P., Kumar, K., Stirnweis, D., Hurni, S., Keller, B., Dhaliwal, H.S., Singh, K. 2012. Identification and mapping of two powdery mildew resistance genes in Triticum boeoticum L. Theor. Appl. Genet. 124:10511058. 
Colmer, T.D., Flowers, T.J., Munns, R. 2006. Use of wild relatives to improve salt tolerance in wheat. J. Exp. Bot. 57:1059-1078.

Cuesta, S., Alvarez, J.B., Guzmán, C. 2017. Identification and molecular characterization of novel LMW-m and -s glutenin genes, and a chimeric -m/-i glutenin gene in 1A chromosome of three diploid Triticum species. J. Cereal Sci. 74:46-55.

Dai, S., Zhao, L., Xue, X., Jia, Y., Liu, D., Pu, Z., Zheng, Y., Yan, Z. 2015. Analysis of high-molecular-weight glutenin subunits in five amphiploids and their parental diploid species Aegilops umbellulata and Aegilops uniaristata. Plant Genet. Res. -Charact. Utiliz. 13:186-189.

Daskalova, N., Doneva, S., Spetsov, P. 2016. Chromosome variation and HMW glutenins in synthetic hexaploid wheats (Triticum turgidum ssp. dicoccum/Aegilops tauschii). Cereal Res. Commun. 44:453-460.

De Santis, M.A., Giuliani, M.M., Giuzio, L., De Vita, P., Lovegrove, A., Shewry, P.R., Flagella, Z. 2017. Differences in gluten protein composition between old and modern durum wheat genotypes in relation to 20th century breeding in Italy. Eur. J. Agron. 87:19-29.

Dhaliwal, H.S., Garg, M., Singh, H., Chhuneja, P., Kaur, H. 2002. Transfer of HMW-glutenin subunits from wild wheats into Triticum durum and improvement of quality. Cereal Res. Commun. 30:173-180.

Elkot, A.F.A., Chhuneja, P., Kaur, S., Saluja, M., Keller, B., Singh, K. 2015. Marker assisted transfer of two powdery mildew resistance genes PmTb7A.1 and PmTb7A.2 from Triticum boeoticum (Boiss.) to Triticum aestivum (L). PLoS ONE 10(6):e0128297.

Goncharov, N.P. 2011. Genus Triticum L. taxonomy: the present and the future. Plant Syst. Evol. 295:1-11.

Gorham, J. 1990. Salt tolerance in the Triticeae: K/Na discrimination in synthetic hexaploid wheats. J. Exp. Bot. 41:623-627.

Halford, N.G., Forde, J., Shewry, P.R., Kreis, M. 1989. Functional analysis of the upstream regions of a silent and an expressed member of a family of wheat seed protein genes in transgenic tobacco. Plant Sci. 62: 207-216.

He, D., Li, H., Xu, S., Duan, X., Zhou, Y., Li, L. 2007. Reaction to powdery mildew and stripe rust in related species and landraces of wheat. Genet. Res. Crop Ev. 54:213-219.

Hu, X.G., Wu, B.H., Yan, Z.H., Liu, D.C., Wei, Y.M., Zheng, Y.L. 2010. Characterization of a novel $1 A y$ gene and its expression protein in Triticum urartu. Agric. Sci. China 9:1543-1552.

Hu, X.G., Wu, B.H., Bi, Z.G., Liu, D.C., Zhang, L.Q., Yan, Z.H., Wei, Y.M., Zheng, Y.L. 2012. Allelic variation and distribution of HMW glutenin subunit 1Ay in Triticum species. Genet. Res. Crop Ev. 59:491-497.

Khan, K., McDonald, E., Banasik, O.J. 1983. Polyacrylamide gel electrophoresis of gliadin proteins for wheat variety. Identification-procedural modifications and observations. Cereal Chem. 60:178-181.

Khoshro, H., Bihamta, M., Hassanii, M., Omidi, M., Aghaei, M. 2010. Length polymorphism at the Glu-A3 and Glu-D3 in wild relatives of wheat. Cereal Res. Commun. 38(3):375-385.

Konopatskaia, I., Vavilova, V., Blinov, A., Goncharov, N.P. 2016. Spike morphology genes in wheat species (Triticum L.). Proc. Latvian Acad. Sci. Section B, Vol. 70:345-355.

Lafiandra, D., D’Ovidio, R., Porceddu, E., Margiotta, B., Colaprico, G. 1993. New data supporting high Mr glutenin subunits as the determinant of quality differences among the pairs $5+10$ vs. $2+12$. J. Cereal Sci. 18: 197-205.

Lage, J., Skovmand, B., Anderson, S.B. 2003. Characterization of greenbug (Homoptera: Aphididae) resistance in synthetic hexaploid wheats. J. Econ. Entom. 90:1922-1928.

Lage, J., Skovmand, B., Anderson, S.B. 2004. Field evaluation of emmer wheat-derived synthetic hexaploid wheat for resistance to Russian wheat aphid (Homoptera: Aphididae). J. Econ. Entom. 97:1065-1070.

Lage, J., Skovmand, B., Peña, R.J., Anderson, S.B. 2006. Grain quality of emmer wheat derived synthetic hexaploid wheats. Genet. Res. Crop Ev. 53:955-962.

Li, H.Y., Li, Z. L., Zeng, X.X., Zhao, L.B., Chen, G., Kou, C.L., Ning, S.Z., Yuan, Z.W., Zheng, Y.L., Liu, D.C., Zhang, L.Q. 2016. Molecular characterization of different Triticum monococcum ssp. monococcum Glu$A 1^{m} x$ alleles. Cereal Res. Commun. 44:444-452.

Liu, H., Sultan, M.A.R.F., Liu, X.I., Zhang, J., Yu, F., Zhao, H.X. 2015. Physiological and comparative proteomic analysis reveals different drought responses in roots and leaves of drought-tolerant wild wheat (Triticum boeoticum). PLoS ONE 10(4):e0121852. 
Lutz, J., Limpert, E., Bartoš, P., Zeller, F.J. 1992. Identification of powdery mildew resistance genes in common wheat (Triticum aestivum L.). I. Czechoslovakian cultivars. Plant Breed. 108:33-39.

Mac Key, J. 2005. Wheat: its concept, evolution and taxonomy, In: Durum wheat breeding: Current approaches and future strategies (eds. C. Royo et al.). Haworth Press, Inc, NY, USA vol. 1, pp. 3-61.

Metakovsky, E.V. 1991. Gliadin allele identification in common wheat. II. Catalogue of gliadin alleles in common wheat. J. Genet. Breed. 45:325-344.

Mujeeb-Kazi, A., Kazi, A.G., Dundas, I., Rasheed, A., Ogbonnaya, F., Chen, P., Kishi, M., Bonnett, D., Wang, R.R.-C., Xu, S., Bux, H., Mahmood, T., Farrakh, S. 2013. Genetic diversity for wheat improvement as a conduit for food security. Adv. Agron. 122:179-259.

Mujeeb-Kazi, A., Ali, N., Ibrahim, A., Napar, A.A., Jamil, M., Hussain, S., Mahmood, Z., Delgado, R., Rosas, V., Cortes, A., Rajaram, S. 2017. Tissue culture mediated allelic diversification and genomic enrichment of wheat to combat production constraints and address food security. Plant Tiss. Cult. Biotech. 27:89-140.

Olson, E.L., Brown-Guedira, G., Marshall, D., Stack, E., Bowden, R.L., Jin, Y., Rouse, M., Pumphrey, M.O. 2010. Development of wheat lines having a small introgressed segment carrying stem rust resistance gene Sr22. Crop Sci. 50:1823-1830.

Payne, P.I., Lawrence, G.J. 1983. Catalogue of alleles for the complex gene loci, Glu-A1, Glu-B1 and Glu-D1 which code for high-molecular-weight subunit in hexaploid wheat. Cereal Res. Commun. 11:29-35.

Radchenko, E.E. 2011. Resistance of Triticum species to cereal aphids. Czech J. Genet. Plant Breed. 47 (Special issue): S67-S70.

Rafique, K., Rasheed, W., Gul, A., Mujeeb-Kazi, A. 2012. Powdery mildew resistance in some new wheat amphiploids $(2 \mathrm{n}=6 \mathrm{x}=42)$ derived from A- and S-genome diploid progenitors. Plant Genet. Res. Charact. Utiliz. 10:165-170.

Ribeiro, M., Bancel, E., Faye, A., Dardevet, M., Ravel, C., Branlard, G., Igrejas, G. 2013. Proteogenomic characterization of novel x-type high molecular weight glutenin subunit 1Ax1.1. Int. J. Mol. Sci. 14: 5650-5667.

Rogers, W.J., Miller, T.E., Payne, P.I., Seekings, J.A., Sayers, E.J., Holt, L.M., Law, C.N. 1997. Introduction to bread wheat (Triticum aestivum L.) and assessment for bread-making quality of alleles from T. boeoticum Boiss. ssp. thaoudar at Glu-Al encoding two high-molecular-weight subunits of glutenin. Euphytica 93: 19-29.

Silva, F.A.S., Azevedo, C.A.V. 2016. The Assistat Software Version 7.7 and its use in the analysis of experimental data. Afr. J. Agric. Res. 11:3733-3740.

Singh, N.K., Shepherd, K.W., Cornish, G.B. 1991. A simplified SDS-PAGE procedure for separating LMW subunits of glutenin. J. Cereal Sci. 14:203-208.

Sood, S., Kuraparthy, V., Bai, G., Gill, B.S. 2009. The major threshability genes soft glume (sog) and tenacious glume $(\mathrm{Tg})$, of diploid and polyploidy wheats, trace their origin to independent mutations at non-orthologous loci. Theor. Appl. Genet. 119:341-351.

Spetsov, P., Plamenov, D., Kiryakova, V. 2006. Distribution and characterization of Aegilops and Triticum species from the Bulgarian Black Sea coast. Centr. Eur. J. Biol. 1:399-411.

Suman, S., Mahal, G.S., Harjit, S. 2004. Effect of transfer of high molecular weight glutenin subunits encoded at Glu-A1 locus of wild Triticum species in Triticum durum. Ind. J. Genet. Plant Breed. 64:28-30.

Trethowan, R.M., Mujeeb-Kazi, A. 2008. Novel germplasm resources for improving environmental stress tolerance of hexaploid wheat. Crop Sci. 48:1255-1265.

Valkoun, J.J. 2001. Wheat pre-breeding using wild progenitors. Euphytica 119:17-23.

van Ginkel, M., Ogbonnaya, F. 2007. Novel genetic diversity from synthetic wheats in breeding cultivars for changing production conditions. Field Crops Res. 104:86-94.

Varzakas, T., Kozub, N., Xynias, I.N. 2014. Quality determination of wheat: genetic determination, biochemical markers, seed storage proteins - bread and durum wheat germplasm. J. Sci. Food Agric. 94:2819-2829.

Villareal, R.L., Sayre, K., Banuelos, O., Mujeeb-Kazi, A. 2001. Registration of four synthetic hexaploid wheat (Triticum turgidum/Aegilops tauschii) germplasm lines tolerant to waterlogging. Crop Sci. 41:274-274.

Zaharieva, M., Ayana, N.G., Al Hakimi, A., Misra, S.C., Monneveux, P. 2010. Cultivated emmer wheat (Triticum dicoccon Schrank), an old crop with promising future: a review. Genet. Res. Crop Ev. 57:937962. 
Zaharieva, M., Monneveux, P. 2014. Cultivated einkorn wheat (Triticum monococcum L. subsp. monococcum): the long life of a founder crop of agriculture. Genet. Res. Crop Ev. 61:677-706.

Zaim, M., Hassouni, K.E., Gamba, F., Filali-Maltouf, A., Belkadi, B., Sourour, A., Amri, A., Nachit, M., Taghouti, M., Bassi, F.M. 2017. Wide crosses of durum wheat (Triticum durum Desf.) reveal good disease resistance, yield stability, and industrial quality across Mediterranean sites. Field Crops Res. 214:219-227.

Zhang, Y., Luo, G., Liu, D., Wang, D., Yang, W., Sun, J., Zhang, A., Zhan, K. 2015. Genome-, transcriptomeand proteome-wide analyses of the gliadin gene families in Triticum urartu. PLoS ONE 10(7):e0131559.

\section{Electronic Supplementary Material (ESM)}

Electronic Supplementary Material (ESM) associated with this article can be found at the website of CRC at https://akademiai.com/loi/0806

Electronic Supplementary Table S1. Number of $\mathrm{F}_{2}$ and $\mathrm{F}_{3}$ plants grown in the field and greenhouse

Electronic Supplementary Table S2. Field performance of 10 genotypes (G) in 2015-2016, developed from the cross SHW8A-Tb/Progres

Electronic Supplementary Table S3. Field performance of three genotypes (G) derived from the cross SHW5A$\mathrm{Tb} /$ Severina for eight traits

Electronic Supplementary Table S4. Glutenins and gliadins in tetraploid wheat genotypes with introgressed seed storage proteins from two amphiploids based on Triticum boeoticum 